\title{
A primitive plant with naked ovule vs a productive fruit tree
}

\section{Opinion}

Flowering was simple in primitive plants and even the whole reproduction process since there was no embryo or zygote. Such plants were absorbing water by what was like a simple diffusion or through special tube-like structures. There was no need to the double fertilization process after the formation of a pollination tube.

Now, in our fruit trees, the picture is much more complicated. The flower contains an enclosed ovule and many tree species require cross pollination and fertilization. However, seeds could not be used as a commercial mean of propagation in the field to obtain the desired traits of the variety or the cultivar. Self incompatibility, either complete or partial, could be a major obstacle for an economic production of many fruits such as almond, some olive cultivars, some mandarin, tangarin, mango, and apple cultivars.

Dichogamy, has been another production problem since the farmer cannot rely on self pollination, Fruit trees with this problem might be protandrous with earlier maturation of pollen grains in a hermaphrodite flower which requires a cultivation of more than one cultivar in the same plot as thecase with walnut, pistash
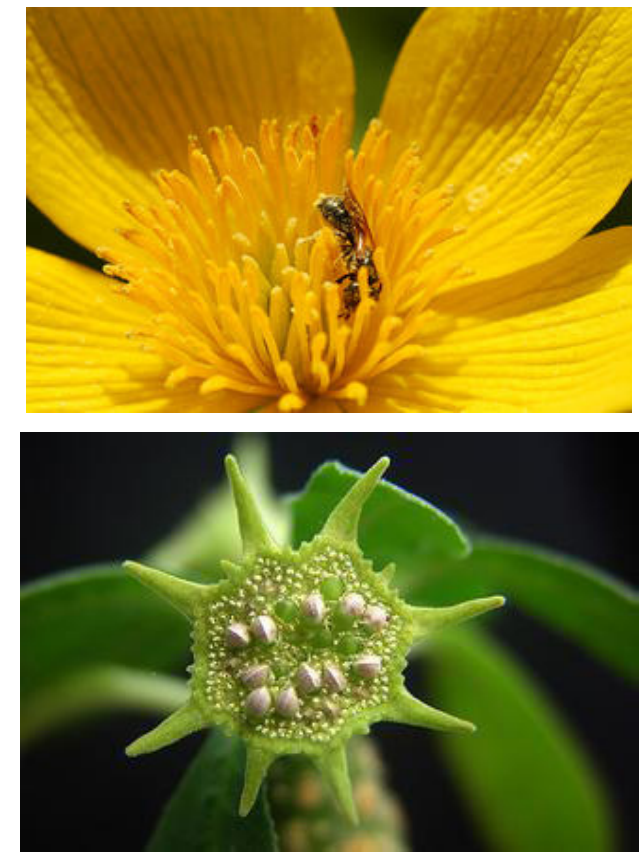

Volume 7 Issue I - 2017

\section{Karim Farag}

Department of Horticulture, Faculy of Agriculture, Damanhour University, Egypt

Correspondence: Karim Farag, Department of Horticulture, Faculty of Agriculture, Damanhour University, Egypt, Email karimmfarag@hotmail.com

Received: April 03, 2017| Published: April 05, 2017

and pecan. The flower could also be a protogenous with earlier maturation of the ovary such as in trees of mango, avocado, and cherimoya. The anther could be also much shorter than the stigma which needs the farmer's help to gain a high fruit set through cross pollination as occurs also with cherimoya flowers. Furthermore, many fruit trees require cross pollination since their pollens have low vigor or dead as in navel orange flowers. The tendency towards cross pollination has been increasing; it might be more complicated, but enhancing yield, productivity and quality.

\section{Acknowledgements}

None.

\section{Conflict of interest}

The author declares no conflict of interest. 